\title{
Combined Teaching Methods of Technical Drawing in Shipbuilding Engineering
}

\author{
Tran Van Tao, Vo Trong Cang \\ Faculty of Transportation Engineering, Ho Chi Minh City University of Technology, Ho Chi Minh City, Vietnam
}

Email address:

tao.tranvan $a$ hcmut.edu.vn (T. V. Tao), vtcang@hcmut.edu.vn (V. T. Cang)

\section{To cite this article:}

Tran Van Tao, Vo Trong Cang. Combined Teaching Methods of Technical Drawing in Shipbuilding Engineering. International Journal of Transportation Engineering and Technology. Special Issue: Transportation Engineering Technology and Education.

Vol. 6, No. 4, 2020, pp. 123-127. doi: 10.11648/j.ijtet.20200604.13

Received: November 12, 2020; Accepted: December 5, 2020; Published: December 11, 2020

\begin{abstract}
Combining the teaching practice and academic analysis, we explored and studied various teaching methods of "Technical Drawing" to stimulate students' interest in learning and to improve the quality of teaching. It mainly includes a good teacher-student relationship, a combination of various teaching methods, good first-lesson, intensive teaching and process evaluation. According to the characteristics of students and the teaching content, the teaching methods can be scientifically set up to achieve good teaching quality and training results. The initial application results are: use in combination with audio-visual equipment such as 3D images on a computer; perform physical models with a miniature scale from on-paper drawings and especially experience group activities during student practice hours. Through this study, at the Ho Chi Minh city University of Technology, VNU-HCM, faculty of Transportation Engineering, we have tried to find ways to alleviate the difficulties, stimulate students' interest in learning in two directions: 1) enrich the imagination of 3D space and 2) increase the introduction of the production knowledge in the most condensed way. The ultimate goal is to improve teaching efficiency in this subject. On the other hand, the products, models, created by students from the subject are also the good models for the next courses.
\end{abstract}

Keywords: Technical Drawing, Ship Building Engineering, Teaching Method, Teaching Quality

\section{Introduction}

"Technical drawing" is an important subject in the group of basic modules of the engineering technology curriculum. It helps students cultivate spatial thinking ability, the ability to configure creative forms, visual thinking, cultural and technical quality together with students' sense of innovation. Technical drawings are the main tools used to express design ideas in engineering design, fabrication and construction. It is very important to train students' basic theoretical knowledge and practical operation ability. Prospective engineers and technicians must master practical operations from basic theoretical knowledge. And that is the goal that should be aimed at achieving the teaching effectiveness of this course.

In teaching, based on the characteristics of teaching content and students' receptive level, we have summarized teaching experience, combined with flexible teaching methods to arouse student's motivation and interest in learning. The following will present some comments and conclusions.

\section{Academic Analysis}

"Technical drawing" is a subject for sophomore students with relatively high enthusiasm for learning. However, some of students find the subject very hard and feel boring when studying due to some reasons. This subject is associated with specialized knowledge, but students have not studied any major, have not practiced production, and lack sensory understanding of expression design techniques [1-4]. On the other hand, the basics of the student's graphic engineering and spatial imagination are not uniform.

Through research on this issue [5-9] we try to find ways to reduce difficulties, stimulate students' interest in learning in two directions: 1) enrich the imagination of zero. and 2) enhancing the introduction of practical manufacturing knowledge in the most condensed way. The ultimate goal is to improve teaching efficiency in this subject. 


\section{Teaching Methods}

\subsection{Good Teacher-student Relationship}

Teacher-student affection will help to understand each other and trust each other. In teaching, teachers should set an example, be strict with themselves and be generous towards others. The teachers' attention will motivate students to actively participate in group activities in class. Students always feel their progress clearly through the teacher's affirmation, which in turn will be more active in learning

\subsection{Combination of Various Teaching Methods}

Drawing courses should be arranged in multimedia classes. Using a combination of audio-visual devices such as 3D images on the computer, combined with physical models to give students specific and vivid knowledge and knowledge. The slides should be compared with the hand-drawn drawings on the blackboard so that students master the projection analysis method and the drawing steps (Figure 1 and figure 2) [10]. This also helps students build their spatial imagination and thinking ability more effectively.
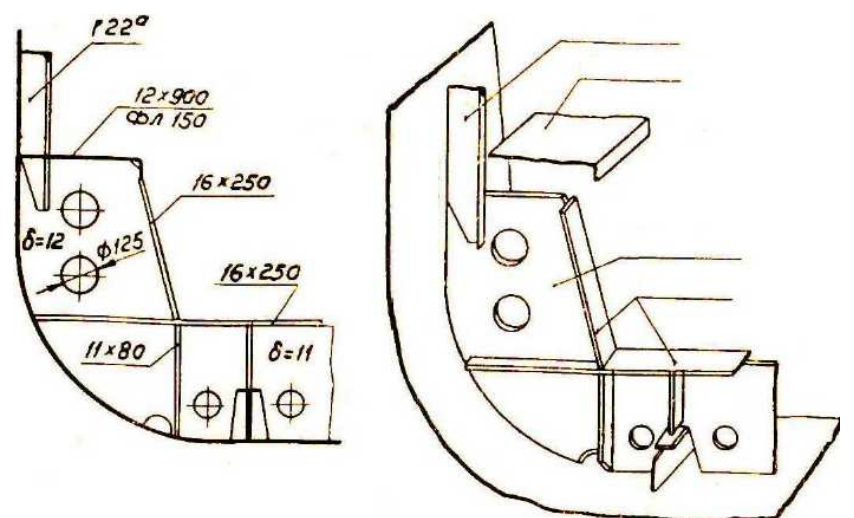

Figure 1. Exercise on structural unit in shipbuilding engineering [10].
The combination of many methods with teaching drawing on the blackboard will increase the visualization, organization and rigor of the content as well as the richness of the content and form of multimedia teaching. This will help improve students' interest in learning and focus attention in the classroom. The lack of manufacturing practices when learning parts and assembly drawings can be presented to students through a combination of multimedia and related video. Through the visual demonstration of multimedia teaching animations, students are easy to understand and accept, thereby improving teaching efficiency and teaching efficiency.

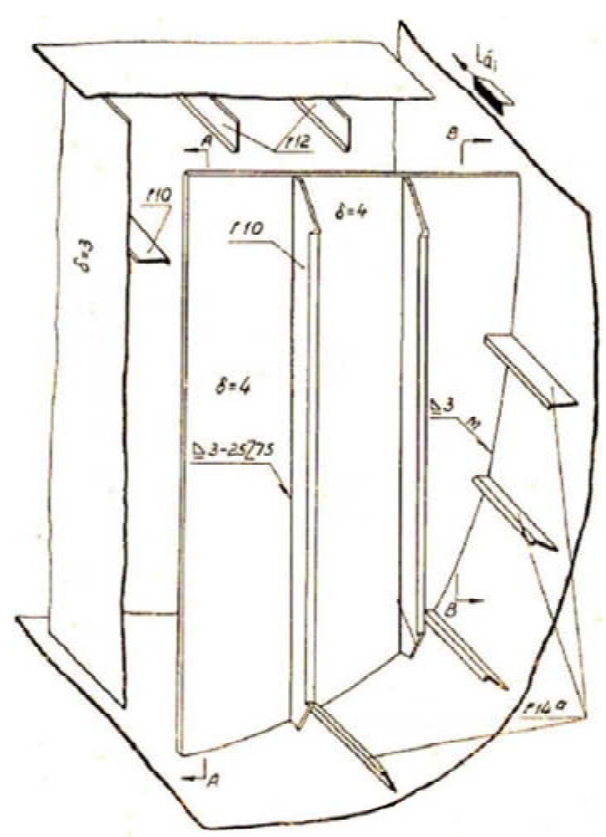

Figure 2. Steel structure exercise in $3 D$ sketch in shipbuilding engineering [10].

For example, figure 3 shows a 3D model of the catamaran hull structure done by a group-practice of previous students [11] (Figure 3).

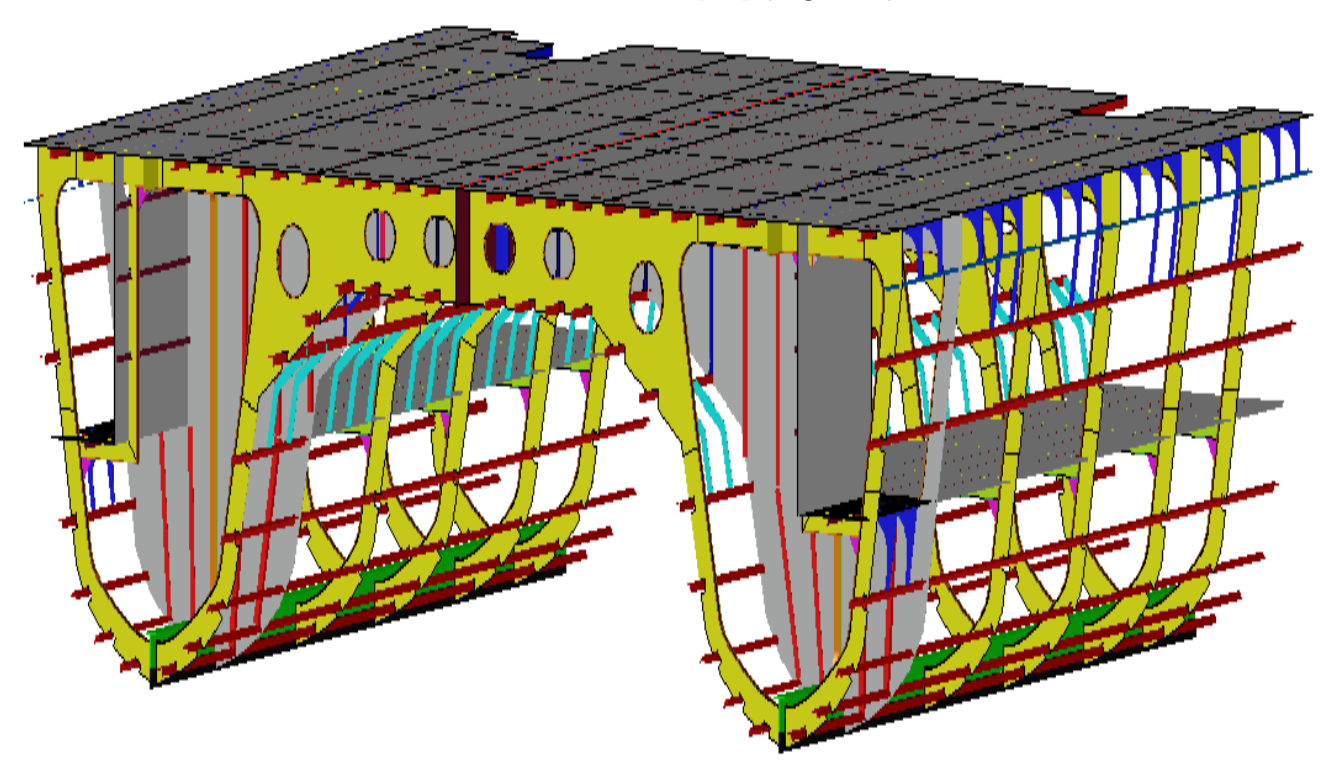

Figure 3. Visual demonstration of a catamaran structure [11]. 


\subsection{Good First Lesson}

The role of the First lesson is especially important because it creates interest for students to learn and has a direct impact on the learning performance behind. "Getting off to a good start is winning half". In the First lesson, students should see some detailed drawings, assembly drawings, products made by CAD and Solidworks (as in figure 4). From there, students will feel the results that they must achieve after completing this course.

\subsection{More Practice}

Technical drawing is a course that requires more practice to master. In teaching, students can use their hands and their brains to complete learning content.

In addition, the implementation of physical models with a miniature scale from on-paper drawings also enhances students' creativity and interest in learning (see from figure 5 to figure 7).

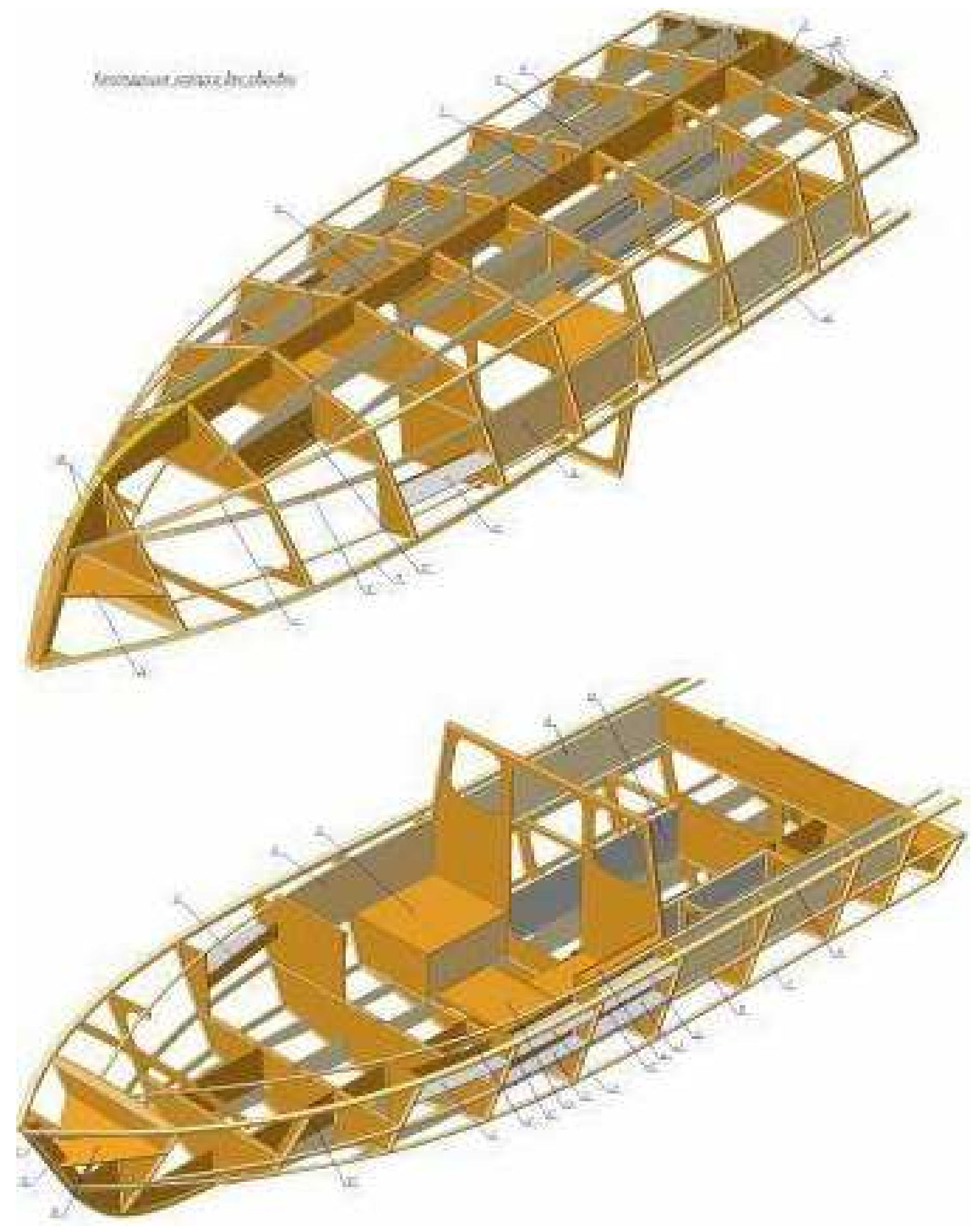

Figure 4. Assembly model of a boat structure made by CAD softwares [11]. 

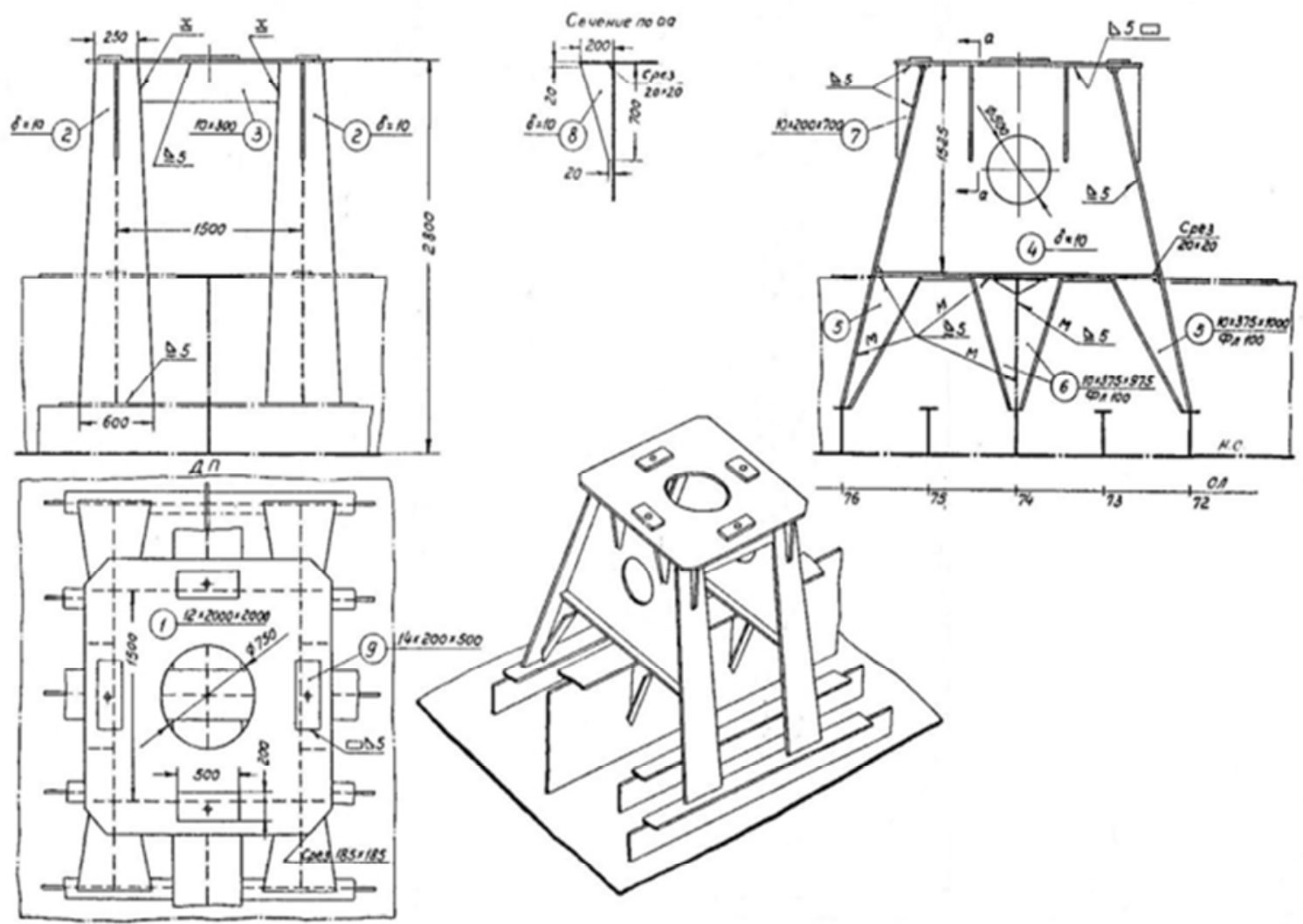

Figure 5. Assembly drawing and isometric view [10].

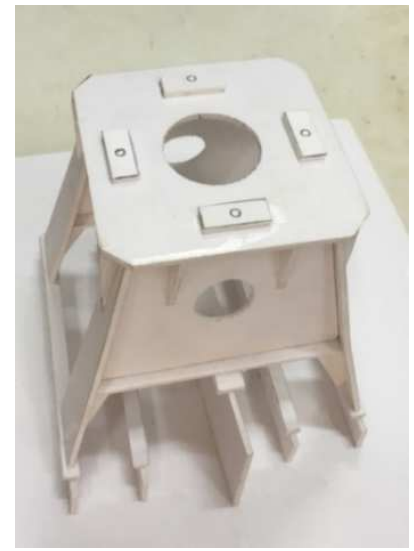

Figure 6. A 1:50 scaled model of a machine base made by students.

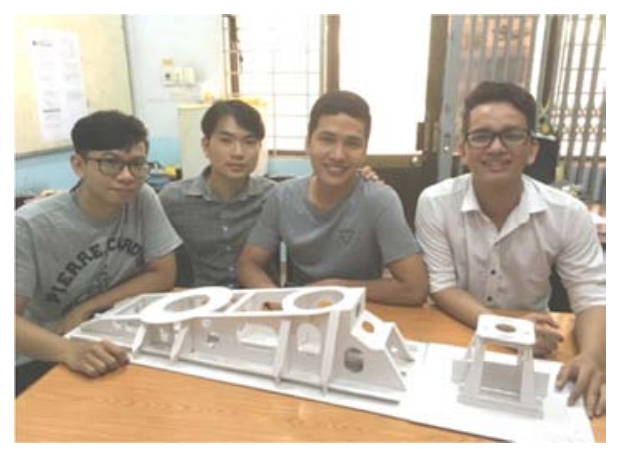

Figure 7. Models made by a student team work [12].

\subsection{Process Assessment}

Mechanical drawing is a step-by-step course. The content before and after is closely related. Requirements when performing an assessment using a 3-step process: Teachers must clearly explain the contents, students do enough exercises, teachers can promptly grasp the learning situation of students through their lessons and homeworks. Through process assessment, supervision and feedback, most students can keep up with the progress of the study. So the process assessment is especially important for this course.

The most important thing in the process evaluation is the routine work. Teachers who grade regular homework into the total score will keep students interested in studying regularly. Students having to seriously complete each assignment are a strong guarantee of learning this course [13, 14].

\section{Summary}

In short, "Technical Drawing" is a basic, practical and practical course. To improve the quality of subject teaching, it is necessary to increase students' excitement with the subject through multimedia teaching, combined with miniature models so that students can easily visualize objects in space [15].

A good, engaging first lesson and timely assessment of the course are the factors that help increase the effectiveness of the subject. And of course, throughout it all is the teacher's 
interest in student learning that reminds and motivates them through every slightest progress.

Through this study, we have tried to find ways to alleviate the difficulties, stimulate students' interest in learning in two directions: 1) enrich the imagination of 3D space and 2) increase the introduction of the production knowledge in the most condensed way. The ultimate goal is to improve teaching efficiency in this subject. On the other hand, the products, models, created by students from the subject are also the good models for the next classes.

\section{References}

[1] Vo Trong Cang, Phan Quang Chanh, Tran Van Tao et al. Ship Construction. ( $2^{\text {nd }}$ ed.) VNU-HCM press, Viet Nam, 2007.

[2] Tran Cong Nghi. Ship drawing. VNU-HCM Press, Viet Nam, 2009.

[3] Tran Cong Nghi. Ship Structure. VNU-HCM press, Viet Nam, 2006.

[4] Ship Structure, Lecture notes, HCMUT, 2013.

[5] Li Xia, Chen Yu, Xin Lixia. Teaching Reform Practice of Mechanical Drawing Course. Science and Technology Information, 2013, (14); 207-207.

[6] Liu Changhua. Exploration on Quality Assurance of Basic Courses in Mechanical Drawing. Technology and Innovation, 2016, 0 (1): 119-119.

[7] Huang Lihong. Mechanical drawing teaching thinking. Contemporary educational practice and teaching research (electronic version), 2017, 0 (3): 130-130.

[8] Meng-li LI and Yue-xia LV. Research on Teaching Methods of Mechanical Drawing. Proc. Int. Conf. on Education Reform, Management and Applied Social Science (ERMASS 2018), 2018, pp 71-73 (ISBN: 978-1-60595-012-9).

[9] Peng Quan. Discussion on the teaching method of mechanical drawing under the application talent training mode. Shandong Industrial Technology, 2018, 0 (5): 185-185.

[10] Pugachov A. S. Collection of tasks for drawing of ship structures $\left(2^{\text {nd }}\right.$ ed.). Leningrad, Shipbuilding Industry Gov. Press. 1960.

[11] Huynh Hoai Phuc, Nguyen Thanh Nhan, Hoang Van Khai, Truong Quoc Khanh, Vo Trong Cang. Building ship structure models for teaching ship structure and technology, Proc. of Young Science Conference - Faculty Transportation
Engineering, University of Technology, VNU-HCM 8/2020, 2020 .

[12] Huynh Hoai Phuc. Building ship structure models for teaching ship structure and technology, R\&D Proj Report, University of Technology, VNU-HCM, 2020.

[13] Ship Drawing. Undergraduate brief course description for 2017 intake at Ho Chi Minh city University of Technology VNU-HCM, 2017.

[14] Technical Drawing for Transportation Engineer. Undergraduate brief course description for 2017 intake at Ho Chi Minh city University of Technology - VNU-HCM, 2017.

[15] Guide on "Making ship structure models", Ho Chi Minh city University of Technology, 2017.

\section{Biography}

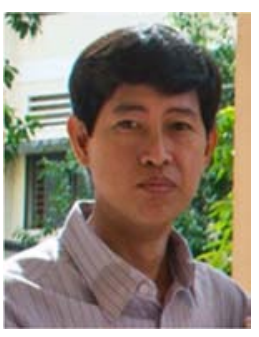

Tran Van Tao (1976, HCM city). Lecturer, Facutly of Transportation Engineering, Ho Chi Minh city University of Technology (HCMUT), Ho Chi Minh city, Viet Nam. Since graduated Master of Engineering in Mechanical Engineering at HCMUT (2005) Mr. Tao has continuously studied and released about 20 scientific publications as well as possitively worked in Naval construction anh ship design field. He is co-author of two instructions on ship construction and using computer in ship design.

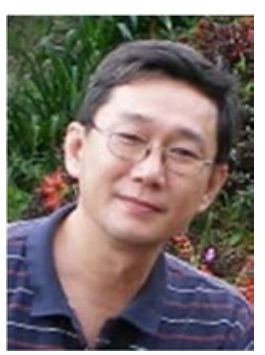

Vo Trong Cang (1961, Saigon). Senior lecturer, Faculty of Transportation Engineering at the Ho Chi Minh city University of Technology (HCMUT). He is former Head of the Department of Naval Architecture \& Marine Engineering, Faculty of Transportation Engineering, HCMUT, Vietnam National University of Ho Chi Minh city (VNU-HCM). In 2015 he has joined with the Science Publishing Group as Lead Guest Editor of the special issue serie titled "Transportation Engineering Technology" of IJMEA, and afterward, Proponent and Editor-in-Chief (from 2016 to 2017) of the International Journal of Transportation Engineering and Technology (IJTET). 